\title{
Spontaneous occlusion of systemic-to-pulmonary arterial shunts
}

\author{
Tom R. Karl
}

\section{Royal Children's Hospital, Melbourne, Australia}

M OTZ AND HIS COLLEAGUES ${ }^{1}$ ADDRESS AN OLD, but still important problem, namely spontaneous occlusion of systemic-topulmonary arterial shunts. With the current emphasis on neonatal repair, as opposed to staging operations, the focus of this discussion has shifted from tetralogy of Fallot and its related lesions to hypoplastic left heart syndrome. Patients undergoing the Norwood operation now comprise in many centers the main group receiving systemicto-pulmonary shunts. An important feature of the strategy for correction of these patients is limitation of pulmonary flow through the use of a small $(3-3.5 \mathrm{~mm})$ shunt. Although these shunts are only required to remain patent for 3-6 months, at which time a bidirectional cavopulmonary shunt is generally performed, the small diameter may render them more likely to occlude than larger shunts. Other factors include pulmonary vascular resistance, the location of the anastomosis, cardiac output, and arterial pressure.

Thrombosis of the shunt in this group is very likely to be fatal. Hence, many units employ some form of anticoagulation, usually aspirin in a dose around $5 \mathrm{mg} / \mathrm{kg} /$ day. This dose is known to provide an

Correspondence to: Tom R. Karl, Royal Children's Hospital, Melbourne, Australia. Fax: ++6139345 6386; E-mail: karl@kryptic.rch.unimelb.edu.au

Accepted for publication 14 June 1999 antiplatelet aggregation effect in adults with various thrombogenic tendencies. Indeed, at the Royal Children's Hospital in Melbourne, we "empirically" administer heparin intravenously at the rate of 10 $\mathrm{IU} / \mathrm{kg} /$ hour. We use this regimen for the first 48 hours following surgery, and then convert to aspirin. Motz and his colleagues advocate the use of aspirin in all children with systemic-to-pulmonary shunts for the lifetime of the shunt. This seems like a reasonable idea, if not a directly reachable conclusion from their data. They make the point that this practice cannot be supported by randomised prospective studies. It is easy to call for such a study in a review of a colleague's research, but more difficult to achieve it, especially when the strategy is already so widely practised, and the drug in question, at the suggested dose, relatively benign. If we want to answer the question, nonetheless, possibly with some adverse results along the way, then a randomised prospective study is what will be required.

Regarding this paper, one can take home the message that, if aspirin is started, then it is best to continue it as long as the shunt is required to stay open.

\section{Reference}

1. Motz R, Wessel A, Ruschewski W, Bürsch J. Reduced frequency of occlusion of aorto-pulmonary shunts in infants receiving Aspirin. Cardiol Young 1999; 9(5): 474-477 